\section{Schwannoma of the greater occipital nerve: An uncommon cause of occipital neuralgia}

Sir,

A 38-year-old man presented with chronic pain in the back of the head on the right side and below the right ear of 2 years duration. There were intermittent episodes of sharp shooting pain radiating upward from the neck with scalp tenderness. The pain would aggravate when he slept supine with the back of the head resting on the bed. There were no complaints of photo or phonophobia, vomiting or visual problems associated with the headache. Various medications had been tried but failed to provide relief. Skin over the right half of the occipital bone (up to the vertex) and below the right ear was hypoesthetic and an ill-defined tender mass was noted on deep palpation in the upper part of the neck on the right side. Magnetic resonance imaging (MRI) of the brain was unremarkable but MRI of the cervical spine showed a circumscribed T2-hyperintense and T1-isointense mass that was enhancing uniformly on contrast present just lateral to the lateral mass of $\mathrm{C} 2$ and $\mathrm{C} 3$ on the right side [Figure 1]. The patient underwent an excision of the mass with complete resolution of his symptoms. Intraoperatively, the lesion was pinkish, firm, and mildly vascular with a clear plane
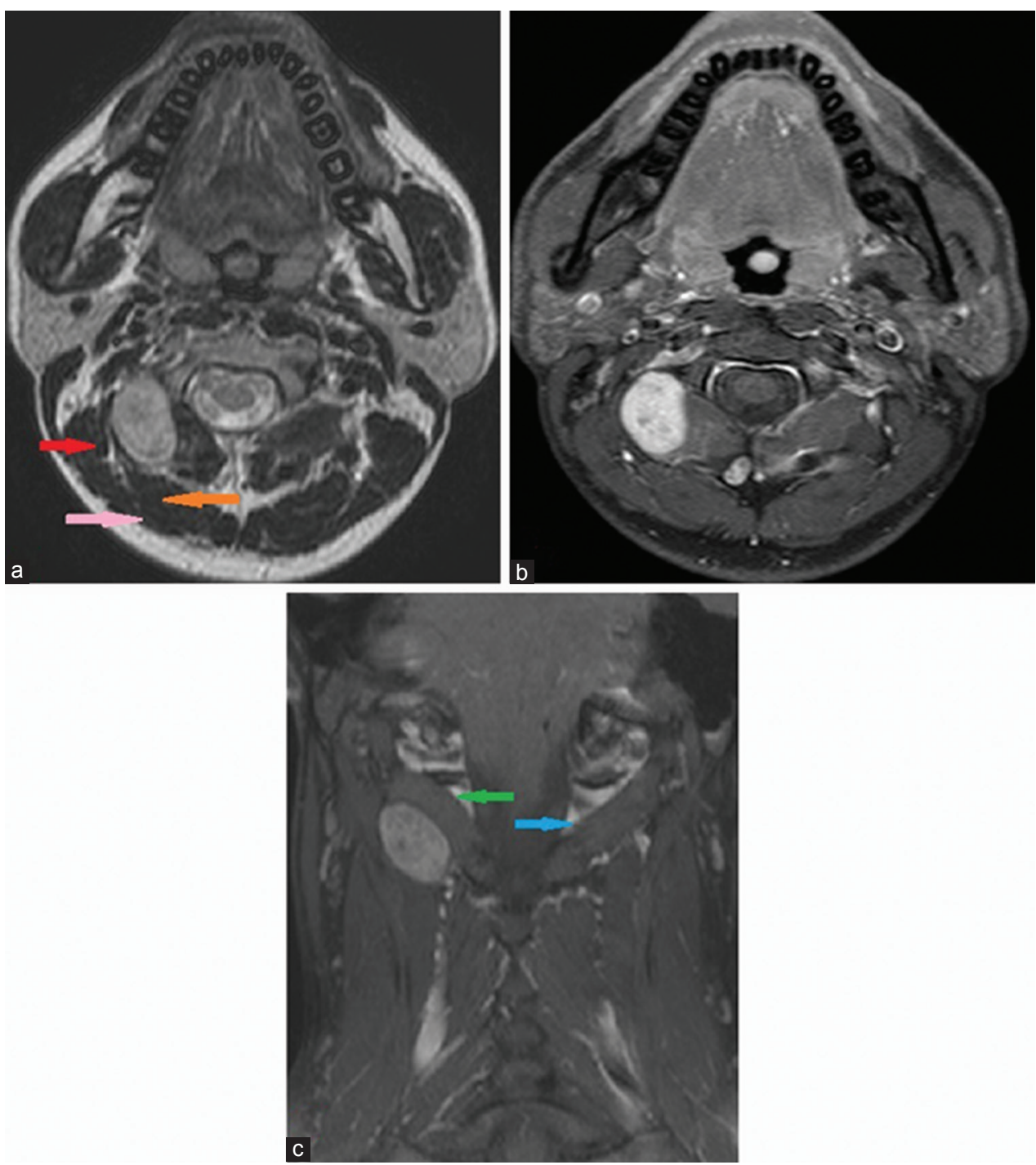

Figure 1: (a) T2-weighted axial images showing a T2-hyperintense lesion deep to the semispinalis capitis (orange arrow), trapezius (pink arrow) and medial to the longissimus capitis (red arrow), (b) T1-weighted postcontrast axial showing lesion is intensely enhancing on contrast (b and c) coronal contrast images showing the inferior oblique muscle on the right side (green arrow) is pushed up by the tumor as opposed to its counterpart on the left side (blue arrow) - a fact that marks out the root of origin to be C2 rather than C1 


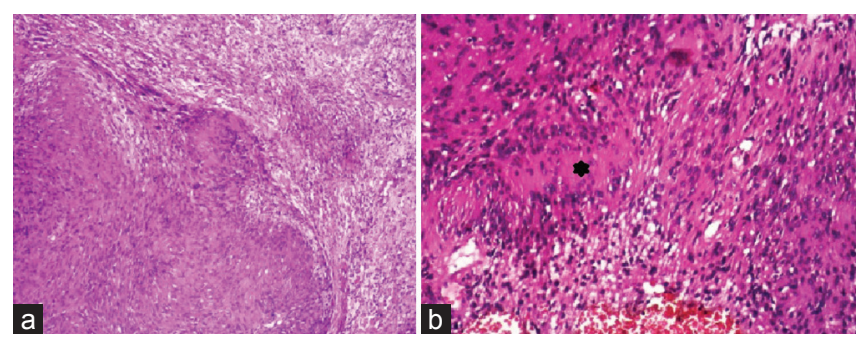

Figure 2: (a) Biphasic pattern of tumor showing hypercellular Antoni $A$ areas on the left and hypocellular Antoni $B$ areas on the right and (b) a Verocay body (black asterisk) with palisading tumor cells in the periphery surrounding the central acellular matrix

of cleavage from surrounding muscles and was attached to the greater occipital nerve (GON) that was sacrificed during surgery. Histopathology [Figure 2] showed a benign spindle cell tumor exhibiting a biphasic pattern with Antoni A (hypercellular with interlacing fascicles of tumor cells and with formation of Verocay bodies) as well as Antoni B (hypocellular with edematous fibro connective tissue and foamy histiocytes) areas. This was reported as schwannoma (WHO Grade 1) and postoperatively he had complete relief of pain.

The GON nerve is the continuation of the medial branch of the posterior ramus of the C2 root and supplies the skin over the occipital bone upto the vertex, below the ear and over the parotid gland. It courses behind the lateral mass of $\mathrm{C} 2$ and over the inferior oblique muscle and penetrates the semispinalis capitis and trapezius muscles before it gives its cutaneous branches. ${ }^{[1]}$ Irritation or injury to this nerve may produce neuralgic pain in its distribution. ${ }^{[2]}$

Though occipital neuralgia is mostly of idiopathic origin or due to speculative entrapment of the GON at various points in its course,$^{[1]}$ structural causes affecting the GON include degenerative disease of the C1-C2 facet joints, ${ }^{[3,4]}$ compression by lymph nodes ${ }^{[5]}$ or vessels, ${ }^{[5,6]}$ trauma to upper cervical spine ${ }^{[7]}$ and direct injury to the nerve. ${ }^{[8,9]}$ The tumorous affliction of the GON as a cause of the occipital neuralgia is decidedly rare. A literature search done in PubMed using the words "greater occipital nerve" and "schwannoma," "arnold's nerve" and "schwannoma," "occipital neuralgia" and "schwannoma," "occipital neuralgia" and "nerve sheath tumours" yielded 7, 1, 7 , and 7 results, respectively. After sorting out those that were not relevant or were repeated, we could find only 5 cases previously reported ${ }^{[10-14]}$ of which two cases ${ }^{[11,13]}$ were involving the C2 root and had a intraspinal component as well. Only three cases have been encountered ${ }^{[10,12,14]}$ where the lesion was purely extraspinal and involving the GON as was seen in our case. In these cases as in ours, palpation of the neck revealed a mass deep to the muscles that was tender. The surgical outcome after the complete resection was satisfactory in both cases.

In conclusion, while treating occipital neuralgia, schwannoma of the GON is seldom thought of as a differential diagnosis particularly in cases like ours where there was no evidence of neurofibromatosis. Routine cranial imaging will not unmask the cause of the pain as the lesion may be well below the foramen magnum. Meticulous palpation of the neck may unmask a swelling and act as a pointer to the diagnosis. In patients with neurofibromatosis and also when the clinical evidence for GON involvement is strong (hypoesthetic areas, Tinel's sign along with the nerve, deep tenderness on palpation, and submuscular swelling) imaging of the cervical spine should be considered as it may clinch a diagnosis amenable to the surgical cure and eliminate the necessity of prolonged and often ineffective medications.

\section{Financial support and sponsorship Nil.}

\section{Conflicts of interest}

There are no conflicts of interest.

Prasad Krishnan, Rajaraman Kartikueyan, Siddhartha Roy Chowdhury, Sayan Das ${ }^{1}$

Department of Neurosurgery, National Neurosciences Centre, ${ }^{1}$ Department of Radiodiagnosis, Peerless Hospital and B. K. Roy Research Centre, Kolkata, West Bengal, India

Address for correspondence: Dr. Prasad Krishnan, Department of Neurosurgery, National Neurosciences Centre, Second Floor, Peerless Hospital Campus, 360 Panchasayar, Garia - 700 094, Kolkata, West Bengal, India. E-mail: prasad.krishnan@rediffmail.com

\section{References}

1. Janis JE, Hatef DA, Ducic I, Reece EM, Hamawy AH, Becker S, et al. The anatomy of the greater occipital nerve: Part II. Compression point topography. Plast Reconstr Surg 2010;126:1563-72.

2. Pascual-Leone A, Pascual-Leone Pascual A. Occipital neuralgia: Another benign cause of "thunderclap headache". J Neurol Neurosurg Psychiatry 1992;55:411.

3. Ehni G, Benner B. Occipital neuralgia and the C1-2 arthrosis syndrome. J Neurosurg 1984;61:961-5.

4. Tancredi A, Caputi F. Greater occipital neuralgia and arthrosis of C1-2 lateral joint. Eur J Neurol 2004;11:573-4.

5. Li F, Ma Y, Zou J, Li Y, Wang B, Huang H, et al. Micro-surgical decompression for greater occipital neuralgia. Turk Neurosurg 2012;22:427-9.

6. Cornely C, Fischer M, Ingianni G, Isenmann S. Greater occipital nerve neuralgia caused by pathological arterial contact: Treatment by surgical decompression. Headache 2011;51:609-12.

7. Clavel M, Clavel P. Occipital neuralgia secondary to exuberant callus 
formation. Case report. J Neurosurg 1996;85:1170-1.

8. Jung SJ, Moon SK, Kim TY, Eom KS. A case of occipital neuralgia in the greater and lesser occipital nerves treated with neurectomy by using transcranial Doppler sonography: Technical aspects. Korean J Pain 2011;24:48-52.

9. Vanelderen P, Lataster A, Levy R, Mekhail N, van Kleef $M$, Van Zundert J. 8. Occipital neuralgia. Pain Pract 2010;10:137-44.

10. Ballesteros-Del Rio B, Ares-Luque A, Tejada-Garcia J, Muela-Molinero A. Occipital (Arnold) neuralgia secondary to greater occipital nerve schwannoma. Headache 2003;43:804-7.

11. Goldhammer L. Second cervical root neurofibroma and ipsilateral migraine headache. Cephalalgia 1993;13:132-4.

12. Ural A, Ceylan A, Inal E, Celenk F. A case of greater occipital nerve schwannoma causing neuralgia. Kulak Burun Bogaz Ihtis Derg 2008;18:253-6.

13. Garza I. Craniocervical junction schwannoma mimicking occipital neuralgia. Headache 2007;47:1204-5.

14. Apaydin M, Varer M, Kalayci OT, Gelal F, Koruyucu MB. Large occipital nerve (Arnold's nerve) schwannoma. JBR-BTR 2013;96:261.
This is an open access article distributed under the terms of the Creative Commons Attribution-NonCommercial-ShareAlike 3.0 License, which allows others to remix, tweak, and build upon the work non-commercially, as long as the author is credited and the new creations are licensed under the identical terms.

\begin{tabular}{|l|l|}
\hline \multicolumn{2}{|c|}{ Access this article online } \\
\hline Quick Response Code: & Website: \\
\hline & www.ruralneuropractice.com \\
\cline { 2 - 2 } & \\
\hline
\end{tabular}

How to cite this article: Krishnan P, Kartikueyan R, Chowdhury SR, Das S. Schwannoma of the greater occipital nerve: An uncommon cause of occipital neuralgia. J Neurosci Rural Pract 2015;6:634-6. 